\title{
Article \\ A Mixed Heterobimetallic Y/Eu-MOF for the Cyanosilylation and Hydroboration of Carbonyls
}

\author{
Estitxu Echenique-Errandonea ${ }^{1,+} \mathbb{D}$, Mireya E. López-Vargas ${ }^{2,+}{ }^{\text {, Juana M. Pérez }}{ }^{2} \mathbb{D}$, Sara Rojas ${ }^{3}$, \\ Duane Choquesillo-Lazarte ${ }^{4}$ (D) José M. Seco ${ }^{1}$, Ignacio Fernández ${ }^{2, * \mathbb{D}}$ and Antonio Rodríguez-Diéguez ${ }^{3, * \mathbb{D}}$
}

\section{check for}

updates

Citation: Echenique-Errandonea, E.; López-Vargas, M.E.; Pérez, J.M.;

Rojas, S.; Choquesillo-Lazarte, D.; Seco, J.M.; Fernández, I.; Rodríguez-Diéguez, A. A Mixed Heterobimetallic Y /Eu-MOF for the Cyanosilylation and Hydroboration of Carbonyls. Catalysts 2022, 12, 299 https://doi.org/10.3390/ catal12030299

Academic Editor: Jorge Bedia

Received: 10 February 2022

Accepted: 2 March 2022

Published: 6 March 2022

Publisher's Note: MDPI stays neutral with regard to jurisdictional claims in published maps and institutional affiliations.

Copyright: (C) 2022 by the authors. Licensee MDPI, Basel, Switzerland. This article is an open access article distributed under the terms and conditions of the Creative Commons Attribution (CC BY) license (https:// creativecommons.org/licenses/by/ $4.0 /)$.
1 Departamento de Química Aplicada, Universidad del País Vasco UPV/EHU, Paseo Manuel Lardizabal, N 3 , 20018 Donostia-San Sebastián, Spain; estitxu.echenique@ehu.eus (E.E.-E.); josemanuel.seco@ehu.es (J.M.S.)

2 Department of Chemistry and Physics, Research Centre CIAIMBITAL, University of Almería, Carretera Sacramento s/n, 04120 Almería, Spain; mireyaestelalv@gmail.com (M.E.L.-V.); jperez.galera88@gmail.com (J.M.P.)

3 Departamento de Química Inorgánica, Facultad de Ciencias, Universidad de Granada, Av. Fuentenueva s/n, 18071 Granada, Spain; srojas@ugr.es

4 Laboratorio de Estudios Cristalográficos, IACT, CSIC-UGR, Av. Las Palmeras $\mathrm{N}^{\circ}$ 4, Armilla, 18100 Granada, Spain; duane.choquesillo@csic.es

* Correspondence: ifernan@ual.es (I.F.); antonio5@ugr.es (A.R.-D.)

$\dagger$ These authors contributed equally to this work.

\begin{abstract}
Herein, to the best of our knowledge, the first heterobimetallic $\mathrm{Y} / \mathrm{Eu}$ porous metal-organic framework (MOF), based on 3-amino-4-hydroxybenzoic acid $\left(\mathrm{H}_{2} \mathrm{~L}\right)$ ligand, with the following formulae $\left\{\left[\mathrm{Y}_{3.5} \mathrm{Eu}_{1.5} \mathrm{~L}_{6}(\mathrm{OH})_{3}\left(\mathrm{H}_{2} \mathrm{O}\right)_{3}\right] \cdot 12 \mathrm{DMF}\right\}_{\mathrm{n}}$ (in advance, namely $\mathbf{Y} / \mathbf{E u}-\mathbf{M O F}$ ), is described. The three-dimensional structure has been synthesized by solvothermal routes and thoroughly characterized, by means of single crystal X-ray diffraction, powder X-ray diffraction, electronic microscopy, ICP-AES, electrophoretic mobility, and FTIR spectra. Intriguingly, the porous nature allows for coordinated solvent molecules displacement, yielding unsaturated metal centers, which can act as a Lewis acid catalyst. This novel supramolecular entity has been tested in cyanosilylation and hydroboration reactions on carbonyl substrates of a diverse nature, exhibiting an extraordinary activity.
\end{abstract}

Keywords: heterobimetallic; metal-organic framework; cyanosilylation; hydroboration; yttrium; europium

\section{Introduction}

Metal-organic frameworks are multifunctional, inorganic-organic systems composed of organic ligands and metallic nodes and, since the 1990s, have emerged as promising materials for infinite applications, among them heterogeneous catalysis [1,2].

Their intrinsic porosity, along with easy tunability and functionalization, are some of the appealing characteristics to be employed in heterogeneous catalysis [3]. The structural porosity provides a confined space to which substrates have access and catalysis can take place. Furthermore, the MOF's robustness provides stable skeletons, where unsaturated metallic centers can act as a Lewis acid catalyst, subsequent displacement of coordinated solvent molecules could occur, and the further activation of the substrates already accessed through the channels might help the catalysis evolve [4].

In this context, cyanosilylation and hydroboration reactions catalyzed by heterogeneous catalysts, such as MOFs, are presented as interesting approaches for the formation of cyanohydrins and alcohols [5,6]. The cyanosilylation reaction is an important synthetic tool for $\mathrm{C}-\mathrm{C}$ bond formation in organic systems, since it gives access to key intermediates of great interest in the field of pesticides and medical application, among which $\alpha$-hydroxy acids, $\alpha$-hydroxy ketones, $\alpha$-amino acids, and $\beta$-amino alcohols can be mentioned $[7,8]$.

Nonetheless, within this frame of reference, the number of reported Ln-MOF acting as a heterogeneous catalyst in the cyanosilylation reaction results were relatively scarce 
(Table S10 summarizes the reported examples exhibiting activity, so far) [5,9-24]. Moreover, to the best of our knowledge, lanthanide-based heterobimetallic MOFs have never been applied. In the field of hydroboration, the context is even more unexplored. The synthesis of alcohols through this route has been explored via MOF systems based on $\mathrm{Ti}, \mathrm{Fe}, \mathrm{Co}$, and Mg [25-30]; however, there are no precedents with these supramolecular entities built on lanthanides precursors. Therefore, in this work, the first example of yttrium and europiumbased mixed MOF, with the formula $\left\{\left[\mathrm{Y}_{3.5} \mathrm{Eu}_{1.5} \mathrm{~L}_{6}(\mathrm{OH})_{3}\left(\mathrm{H}_{2} \mathrm{O}\right)_{3}\right] \cdot 12 \mathrm{DMF}\right\}_{\mathrm{n}}$, is presented, taking the strong background of our group in the examination of these supramolecular systems in catalysis $[15,16]$.

The heterobimetallic Y/Eu-MOF presented herein was designed when looking for a synergy and enhanced catalytic activity, with respect to their isostructural pristine counterparts, which were able to exhibit activity for seven cycles, with very low catalytic loading of $0.5 \mathrm{~mol} \%$, no catalyst leaking, TOF values of $106 \mathrm{~h}^{-1}$ and $1031 \mathrm{~h}^{-1}$, and preferred suitability towards aldehydic and ketonic substrates for Y-MOF [15] and Eu-MOF, respectively.

Taking all into consideration, our interest lies in exploring the catalytic activity of this novel heterobimetallic MOF, based on 3-amino-4-hydroxybenzoic acid polytopic ligand, in the cyanosilylation and hydroboration reactions of aldehydes and ketones of diverse nature under solvent-free and environmentally friendly conditions, in order to eventually conclude whether catalytic activity enhances, with respect to initial counterparts.

\section{Results and Discussion}

\subsection{Preparation of the Catalyst}

The solvothermal reaction between 3-amino-4-hydroxybenzoic acid $\left(\mathrm{H}_{2} \mathrm{~L}\right)$ ligand and $\mathrm{Y}$-Eu metal mixture in a basic media yields a three-dimensional, porous, metal-organic framework that crystallizes in hexagonal $P 63 / m$ space group. The asymmetric unit of this supramolecular entity is composed of a deprotonated ligand molecule, two metal atoms with special positions (in addition to a coordinated water molecule), and a hydroxyl bridge, which acts as connector among neighboring metallic centers. Note that, taking into consideration that metals are randomly distributed within the crystal structure, a tentative formula is presented, which is corroborated by bulk properties of the material (see ICP-AES results in Table S2 or SEM-EDX results in Figure S3).

Therefore, regarding the metal environment, two surroundings are described: nine coordinated $\mathrm{MN}_{3} \mathrm{O}_{6}$ and eight coordinated $\mathrm{MO}_{8}$ environments, which, according to continuous shape measurements, confirm the spherical capped square antiprism (TCTPR-9) and triangular dodecahedron (TDD-8) polyhedra, respectively. The former coordination environment is composed of three hydroxyl oxygens and amino atoms from $\mathrm{L}$ in addition to three additional oxygen atoms belonging to ligand hydroxyl group. The latter metallic nucleus is composed of the coordination of a water solvent molecule, an oxygen belonging to a hydroxyl bridge, along with six oxygen atoms, corresponding to two ligand hydroxyl and two carboxylate moieties.

As aforementioned, hydroxyl bridges $\mu_{3}-\mathrm{OH}^{-}$join metallic centers constructing $\mathrm{M}_{5}(\mathrm{OH})_{3}$ secondary building units in the structure, being the ligand connector, among different sbu. Regarding the connectivity of the supramolecular entity, from the topological point of view, six-connected nodes are described, which, according to TOPOS software [31] examination, the framework disposed of the acs network with the $\left(4^{9} \cdot 6^{6}\right)$ point symbol. Intrinsic porosity, characterized by three dimensional micropores of $10.1 \times 13.3 \AA$ of $\mathbf{Y} / \mathbf{E u}$ MOF (according to PLATON-v1.18 [32] cavities, corresponds to 19\% of the volume of the structure) and enables solvent crystallization molecules to be trapped, whiting the pores; concretely, DMF molecules have been demonstrated to be located in the microchannels (Figure 1). 
a)

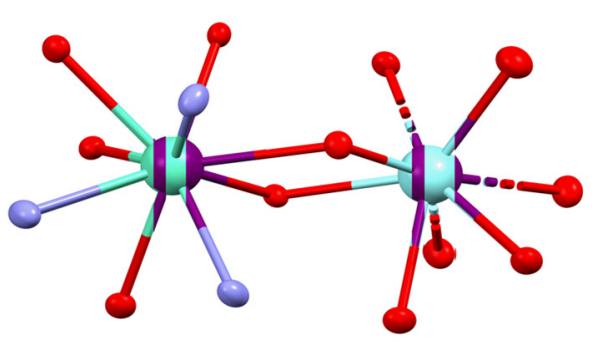

c)

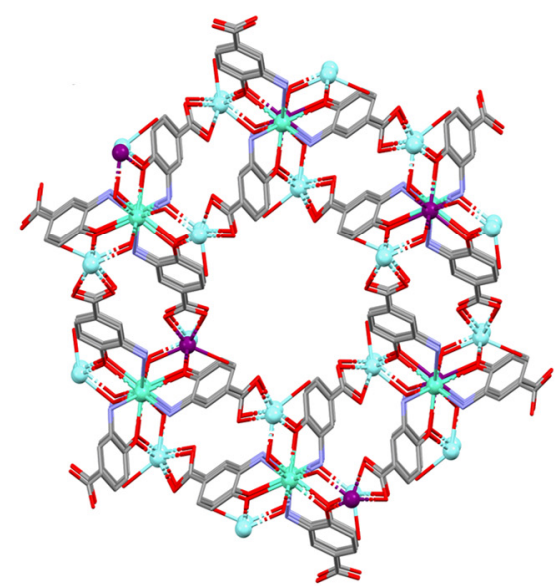

b)

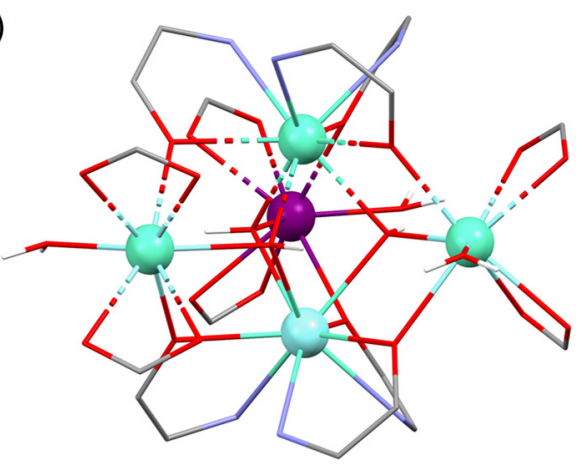

d)

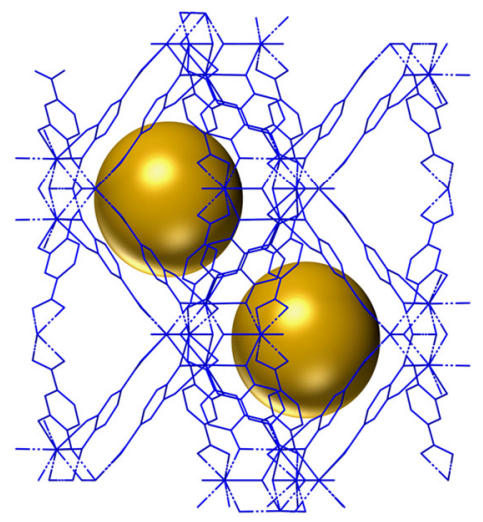

Figure 1. Perspective view of the (a) metal coordination environments found in heterobimetallic compound Y/Eu-MOF. (b) View of the pentametallic nodous, where $\mathrm{M}_{5}(\mathrm{OH})_{3}$ sbu are appreciable. (c) View for the formation of the $1 \mathrm{D}$ channels; (d) the cavities present in the structure along the $a$ axis. Color code: Y (green), Eu (purple), C (grey), O (red), N (blue), and H (white). Note that, due to the altering and randomly oriented disposition metals, an approximated representation has been performed, taking into consideration proposed formula of $\left\{\left[\mathrm{Y}_{3.5} \mathrm{Eu}_{1.5} \mathrm{~L}_{6}(\mathrm{OH})_{3}\left(\mathrm{H}_{2} \mathrm{O}\right)_{3}\right] \cdot 12 \mathrm{DMF}\right\}_{\mathrm{n}}$.

\subsection{Chemical Composition}

Single-crystal X-ray diffraction allowed for proposing an approximated formula of the heterobimetallic catalyst, which was further confirmed by FT-IR, ICP-AES, PXRD, and SEM-EDX. For a detailed explanation of PXRD and FT-IR, please check supporting information, Figures S1 and S2, respectively.

ICP-AES analysis, conducted in the heterobimetallic compound Y/Eu-MOF, exhibited

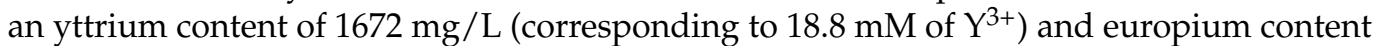
of $1268 \mathrm{mg} / \mathrm{L}\left(8.34 \mathrm{mM} \mathrm{Eu}^{3+}\right)$. The calculated $\mathrm{Y}$ to Eu relationship gives 2.25, which is very much in line with the proposed formula, where a proportion of 2.33 is expected. Additionally, SEM-EDX mapping confirms that both metals are present in single crystal. However, the mapping spectrum, performed in one single crystal, showed relatively higher $\mathrm{Y}^{3+}$ to $\mathrm{Eu}^{3+}$ proportions; for the crystal in which spectrum was collected, a relationship of 3.25, regarding to $\mathrm{Y}$ to $\mathrm{Eu}$, was calculated. This is due to the uneven distribution of metals throughout the catalyst structure. Nonetheless, the proposed formula, which is derived by single crystal X-ray diffraction, powder X-ray diffraction, SEM-EDX, and ICP-AES, is consistent and summarizes the best approximation for data obtained in the aforementioned techniques.

\subsection{Chemical Stability and Electrophoretic Behavior}

$\zeta$-potential is one of the fundamental parameters normally used to measure the magnitude of the electrostatic (or charge) repulsion or attraction between particles, being an 
indirect estimate of the surface charge density of the systems and helping to determine the repulsive interactions between colloidal particles, as well as the tendency of aggregation. Systems with high $\zeta$-potential $\left({ }^{-} /^{+}\right)$are considered electrically stable, whereas colloids with low $\zeta$-potential $\left({ }^{-} /^{+}\right)$are usually referred to as systems that tend to aggregate and further precipitate. In this study, measurements were always conducted at a fixed conductivity of $330 \mu \mathrm{S} / \mathrm{cm}$, which is equivalent to a concentration of about $3.7 \mathrm{mM} \mathrm{NaCl}$ (Figure S7). The highest negative value of the $\zeta$-potential, obtained with $\mathbf{Y} / \mathbf{E u}-\mathbf{M O F}$, was reached at $\mathrm{pH} 10(-35.8 \pm 0.5 \mathrm{mV}$, electrophoretic mobility of $-2.252 \pm 0.035 \mu \mathrm{mcm} / \mathrm{Vs})$, suggesting that: (i) the dissociation of external acidic groups have occurred, conferring the overall negative charge (Figures S8 and S9, Table S7); (ii) the MOF particles will tend to repel each other, and there will be no tendency for the particles to come together at this basic $\mathrm{pH}$, due to this large value of $\zeta$-potential. However, when reducing the $\mathrm{pH}$ of the solutions, the $\zeta$-potentials values started to increase, evidencing an isoelectric point between $\mathrm{pH} 4$ and 5. Similar results were previously reported by our group. The Eu-MOF catalyst, with the highest negative value of $\zeta$-potential, was also obtained at pH $10(-25.0 \pm 0.6 \mathrm{mV})$; however, in this case, the isoelectric point was obtained between $\mathrm{pH} 8$ and 9 (Figure 2). From an electrophoretic behavior point of view, the mixed nature of MOF confers both a higher stability, as a function of $\mathrm{pH}$, and less tendency to aggregate.

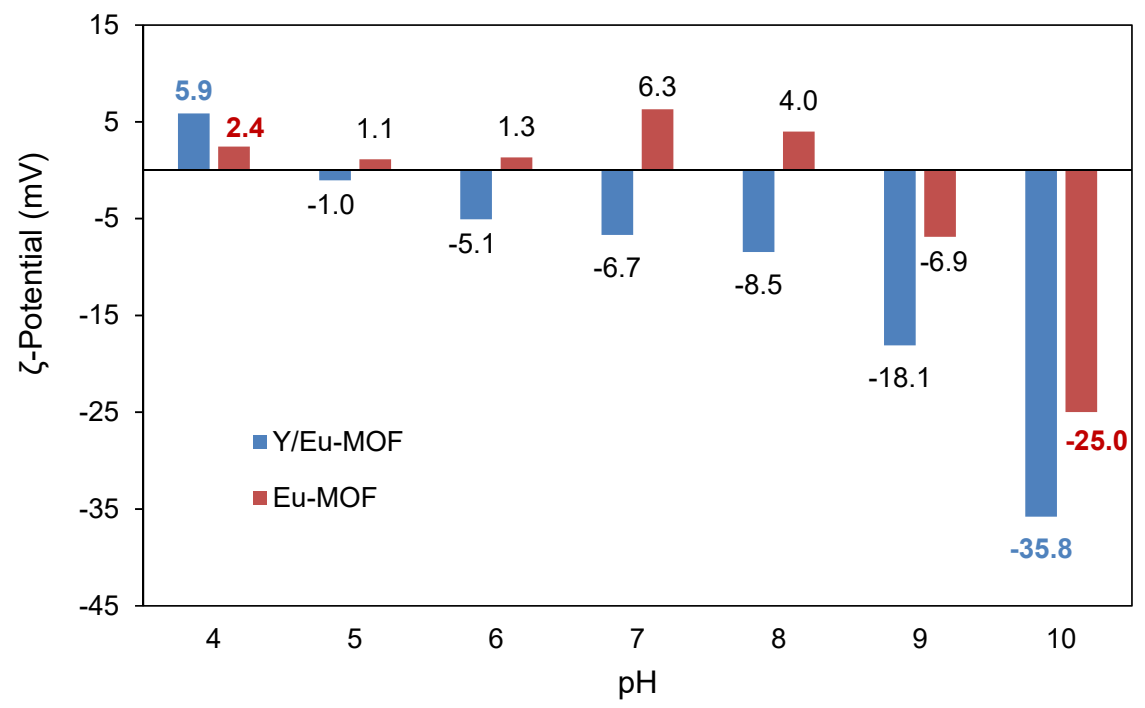

Figure 2. Comparison of $\zeta$-potential behavior, as a function of $\mathrm{pH}$, obtained with Y/Eu-MOF and Eu-MOF. All the measurements were performed with a constant conductivity of $330 \mu \mathrm{S} / \mathrm{cm}$.

In order to determine the particle size distribution of the catalyst in the suspended and deposited fraction, optical microscope images were assayed (Figures S4 and S5). The catalyst was suspended in distilled water; the suspension was shaken vigorously and subsequently left for sedimentation for $5 \mathrm{~min}$, and the suspended fraction separated. The deposited fraction was composed of $68 \%$ of the total amount of catalyst initially weighted, having an average particle size distribution of $12 \pm 6 \mu \mathrm{m}$ (Figure S4). The suspended fraction showed an average particle size of $8 \pm 4 \mu \mathrm{m}$ (Figure S5). Obtained values are relatively similar to SEM images, in which single crystals and larger aggregates are appreciated. Taking into consideration the average particle size distribution in the suspension, it is suggested that single-crystals remain relatively well-suspended, and aggregates of superior size tend to deposit.

\subsection{Study of the Catalytic Activity}

The catalytic activity of $\mathbf{Y} / \mathbf{E u}-\mathbf{M O F}(0.5 \mathrm{~mol} \%)$ was initially evaluated in the cyanosilylation reaction of carbonyl compounds (Y/Eu-MOF) using TMSCN as the nucleophile, solvent free reaction conditions, room temperature, and $\mathrm{N}_{2}$ atmosphere. These conditions 
have been already reported in our previous works, with monometallic $\mathrm{Y}$ or Eu MOF synthetized with the same ligand $\mathrm{H}_{2} \mathrm{~L}$ (3-amino-4-hydroxybenzoic acid) [15], obtaining only $8 \%$ conversion after $14 \mathrm{~h}$ when the blank reaction was tested.

The scope of the reaction was evaluated with five highly reactive aldehydes of different natures, such as aromatic, heteroaromatic, and aliphatic, demonstrating that independently of the nature of the substituent, the reaction takes place with very good to excellent conversions (89-99\%), after only $24 \mathrm{~h}$ (Scheme 1). Later on, less reactive and sterically demanding ketones were tested, observing a significant decrease in conversion (74-77\%), when electron-donating or -withdrawing substituents were located at the para-position, whereas, again, excellent conversion were achieved with aromatic, heteroaromatic, and aliphatic substrates (91-99\%) (Scheme 1). These results overpass the ones published, until the moment for other groups [21-23], and have similar catalytic behaviour with our pristine Eu-MOF.

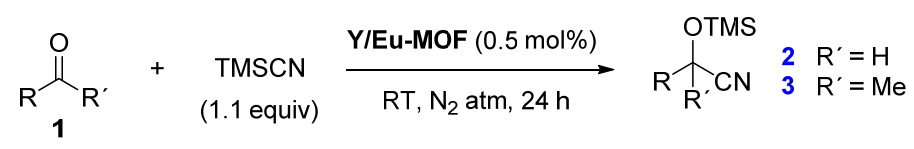<smiles>COC(C#N)c1ccccc1</smiles>

2a (>99\%)<smiles>CCC(C#N)[O+]S(C)(=O)=O</smiles>

2 e $(>99 \%)$<smiles>C[AsH3+]OC(C#N)(C#N)c1ccc(F)cc1F</smiles>

3d $(91 \%)$<smiles>COc1ccc(C(C#N)O[Na])cc1</smiles>

2b (89\%)<smiles></smiles>

3a (>99\%)<smiles>C[O+]C(C)(C#N)c1ccccn1</smiles>

3e $(94 \%)$<smiles>COC(C#N)c1ccc(Cl)cc1</smiles>

2c $(>99 \%)$<smiles>COc1ccc(C(C)(C#N)[O+]S(C)(=O)=O)cc1</smiles>

3b $(77 \%)$<smiles>CCC(C#N)(O[Na])O[Na]</smiles>

$3 f(>99 \%)$<smiles>COC(C#N)c1ccccn1</smiles>

2d $(>99 \%)$<smiles>CC(C#N)([O+]S(C)(=O)=O)c1ccc(Cl)cc1</smiles>

3c $(74 \%)$<smiles></smiles>

$3 \mathbf{g}(>99 \%)$

Scheme 1. Scope of the cyanosilylation reaction using aldehydes and ketones.

As a continuation of the study of the catalytic activity of Y/Eu-MOF, we decided to go one step forward and test, for the first time, the hydroboration reaction of carbonyl compounds with a lanthanide based-MOF catalyst. For that, the optimization of the reaction conditions was carried out (Table S8). First of all, the reaction was tested with solvents of different natures, as well as without solvent (entries 1-5), obtaining the best result in the absence of solvent (entry 1, Table S8). Finally, the amount of catalyst was also tested (entries 6-8), observing that, with a slight increase from 0.35 to $0.5 \mathrm{~mol} \%$, the reaction took place with full conversion (entry 6).

With the optimal reaction conditions in hand, the scope of the reaction was evaluated again, using a broad range of different ketones (Scheme 2). The use of electron-donating groups in the para-position of the aromatic ring negatively influenced the catalytic reaction, causing the reaction time to increase from 24 to 48 or even $120 \mathrm{~h}$, in order to obtain moderate conversions (45-67\%). This influence on the increase in reaction time did not take place when electron-withdrawing substituents were used, observing that, regardless of the position of the aromatic ring in which the substituents were found, yields were good (71-90\%). Furthermore, heteroaromatic ketones reached good results in only $24 \mathrm{~h}$ of reaction (88\%). The steric hindrance of ketones, such as $\mathbf{1} \mathbf{j}$ and $\mathbf{1} \mathbf{p}$, needed superior reaction times of 48 and $120 \mathrm{~h}$, respectively, in order to achieve full conversion. Aliphatic ketones, with different natures, were tested and provided good results (95-99\%). Then, we decided to test cyclic ketones, which are usually less employed, obtaining moderate results 
(61-63\%). Finally, the chemoselectivity of the reaction was pursued by employing ketones bearing double bonds and ester groups, achieving, in both cases, the specific reduction of the carbonyls; although, in the latter, the conversion was lower than $5 \%$, due to the poor solubility of the substrate in HBpin.

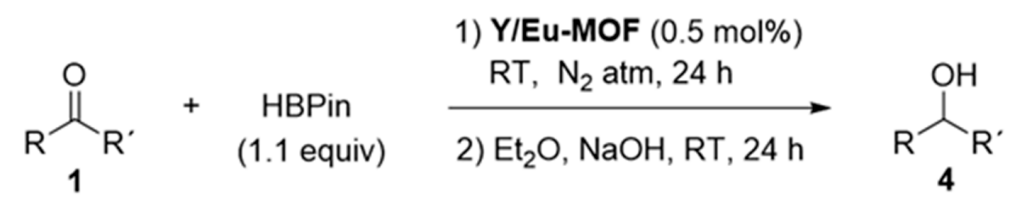<smiles>CC(O)c1ccccc1</smiles>

4a (95\%)<smiles>CC(O)c1cccc(Cl)c1</smiles>

4 e $(80 \%)$<smiles>CC(O)c1ccccn1</smiles><smiles>[13CH3]</smiles><smiles>CCC(C)O</smiles>

$4 \mathrm{~m}(>99 \%)$<smiles>CC(C)Cc1ccc(C(C)O)cc1</smiles>

4b $(67 \%)^{b}$<smiles>CC(O)c1ccccc1Cl</smiles>

4f $(90 \%)$<smiles>OC(c1ccccc1)c1ccccc1</smiles>

4j $(>99 \%)^{b}$<smiles>OC1CCCCC1</smiles>

4n (95\%)<smiles>COc1ccc(C(C)O)cc1</smiles>

$4 c(45 \%)^{c}$<smiles>CC(O)c1ccc(F)cc1F</smiles>

4g (77\%)<smiles>OC(/C=C/c1ccccc1)c1ccccc1</smiles>

4k $(>99 \%)^{\text {b }}$<smiles>OC1CCCc2ccccc21</smiles>

$40(61 \%)$<smiles>CC(O)c1ccc(Cl)cc1</smiles>

$4 d(71 \%)$<smiles>OC(c1ccc(F)cc1)C(F)(F)F</smiles>

4h (71\%)<smiles>COC(=O)c1ccc(C(C)O)cc1</smiles>

4 I $(<5 \%)^{c}$<smiles>OC1C2CC3CC(C2)CC1C3</smiles>

$4 p(63 \%)^{c}$

Scheme 2. Scope of the hydroboration reaction of ketones. Reaction carried out for $24 \mathrm{~h} .{ }^{\text {a }}$ Reaction carried out during $24 \mathrm{~h} ;{ }^{\mathrm{b}}$ Reaction carried out during $48 \mathrm{~h} ;{ }^{\mathrm{c}}$ Reaction carried out during $120 \mathrm{~h}$.

Another important issue that needed to be addressed was if our catalysis was the object of hidden boron catalysis [33]. To distinguish between "true" catalysis and $\mathrm{BH}_{3}$ catalysis, for reactions using HBpin, we performed two complementary experiments. With the help of ${ }^{1} \mathrm{H}$ and ${ }^{11} \mathrm{~B}$ NMR, we pursued the possible MOF-promoted $\mathrm{BH}_{3}$ formation by monitoring the mixture of our MOF catalyst and HBpin under catalytic conditions. The lack of $\mathrm{BH}_{3}$ signals was evidenced during the whole experiment, proving that our MOF catalyst does not promote formation of $\mathrm{BH}_{3}$. In addition, we performed the hydroboration of acetophenone with $\mathrm{BH}_{3} \cdot \mathrm{THF}$, instead of with $\mathrm{HBpin}$, showing no substrate conversion and, therefore, further verifying that, under our catalytic conditions, hidden boron catalysis does not exist.

\subsection{Recyclability and Leaching Studies of the Catalyst}

Recyclability tests were also investigated, in order to study the heterogeneous nature of the catalyst. After standard reaction conditions, using acetophenone as substrate (Schemes S1 and S2), the catalyst was isolated from the reaction mixture via centrifugation and washed several times with dichloromethane. The catalyst was dried under vacuum 
and then charged with a new set of reagents, in order to evaluate its recyclability. The corresponding products were obtained in a $28 \%$ and $61 \%$ for cyanosilylation and hydroboration, respectively, and, in another consecutive cycle, $0 \%$ and $15 \%$ of conversion, respectively, was achieved (Figure S10). A leaching test was also carried out, in the case of the hydroboration reaction (Scheme S3). For that, after the first and second reaction of recyclability test, the catalyst was removed by centrifugation and supernatant was filtered through a plug of celite and dried under vacuum. Then, 1-(pyridin-2-yl)ethan-1-one (1i) and HBpin were added to the crude of the corresponding reaction cycle, and the reaction was stirred under inert $\mathrm{N}_{2}$ atmosphere at room temperature for $24 \mathrm{~h}$. After that time, an aliquot was analysed by ${ }^{1} \mathrm{H}$ NMR, obtaining, in the first cycle, a $38 \%$ of conversion and, in the second cycle, a $13 \%$ of product, corroborating the leaching of $\mathrm{Y}$ or $\mathrm{Eu}$.

\subsection{Green Chemistry Metrics}

Green chemistry metrics such as atomic economy (AE), mass intensity (MI), reaction mass efficiency (RME), and carbon efficiency (CE) were calculated for both reactions studied (Table S9), in order to evaluate if the reactions are eco-friendly and can overcome environmental and health problems. The obtained values for cyanosilylation reaction were $100 \%$ of $\mathrm{AE}, 1.127$ for MI, $95.7 \%$ for RME, and $96.8 \%$ for CE. These results are comparable to those described previously for related lanthanide-based MOFs $[15,16,19,20]$. In the case of the hydroboration reaction, these values decreased considerably, down to $49.1 \%, 2.406$, $46.8 \%$, and $52.1 \%$ for $\mathrm{AE}, \mathrm{MI}, \mathrm{RME}$, and $\mathrm{CE}$, respectively, due to the final hydrolysis and consequent loss of atoms in the final product (Table S9).

\section{Materials and Methods}

\subsection{Materials}

All experiments involving moisture-sensitive compounds were performed under an inert atmosphere of $\mathrm{N}_{2}$ using standard techniques. Unless otherwise indicated, reagents and substrates were purchased from commercial sources and used as received. Metallic precursors, such as europium (III) nitrate pentahydrate (99.9\%, Alfa Aesar), and yttrium (III) nitrate hexahydrate (99.9\% of purity, Fluorochem), were used as received, as well as 3amino-4-hydroxybenzoic acid ligand $\left(\mathrm{H}_{2} \mathrm{~L}, \mathrm{C}_{7} \mathrm{H}_{7} \mathrm{NO}_{3}, 97 \%\right.$ of purity), which was purchased from Fluorochem. Solvents not required to be dry were purchased as technical grade and used as received. Conversion values relative to the limiting reagent were calculated from the ${ }^{1} \mathrm{H}$ NMR spectra of the reaction crudes. Isolated products of cyanosilylation reaction were obtained after centrifugation $\left(12,300 \mathrm{rpm}, 5 \mathrm{~min}, 20^{\circ} \mathrm{C}\right)$ and washed with dichloromethane $(2 \times 0.5 \mathrm{~mL})$, in order to remove the catalyst or column chromatography in silica gel using hexane as eluent. For the hydroboration reaction, first of all the hydrolysis of the product was carried out adding $\mathrm{NaOH}(0.1 \mathrm{M}, 0.5 \mathrm{~mL})$ and $\mathrm{Et}_{2} \mathrm{O}(0.5 \mathrm{~mL})$ and stirring the mixture overnight; after that, the catalyst was removed via centrifugation $\left(12,300 \mathrm{rpm}, 5 \mathrm{~min}, 20^{\circ} \mathrm{C}\right)$ and washed with dichloromethane $(2 \times 0.5 \mathrm{~mL})$.

\subsection{Synthesis of Catalyst and General Procedures of Catalysis}

Synthesis of $\left\{\left[\mathrm{Y}_{3.5} \mathrm{Eu}_{1.5} \mathrm{~L}_{6}(\mathrm{OH})_{3}\left(\mathrm{H}_{2} \mathrm{O}\right)_{3}\right] \cdot \mathbf{1 2 D M F}_{n}\right.$, namely Y/Eu-MOF: The 3-amino4-hydroxybenzoic acid $(0.010 \mathrm{~g}, 0.0625 \mathrm{mmol})$ was dissolved in $0.2 \mathrm{~mL}$ of DMF containing $10 \mu \mathrm{L}$ of $\mathrm{Et}_{3} \mathrm{~N}(0.072 \mathrm{mmol})$. In a separate vial, $\mathrm{Eu}\left(\mathrm{NO}_{3}\right)_{3} \cdot 5 \mathrm{H}_{2} \mathrm{O}(0.006 \mathrm{~g}, 0.0145 \mathrm{mmol})$ and $\mathrm{Y}\left(\mathrm{NO}_{3}\right)_{3} \cdot 6 \mathrm{H}_{2} \mathrm{O}(0.011 \mathrm{~g}, 0.0289 \mathrm{mmol})$ salts were dissolved into a $0.8 \mathrm{~mL}$ of distilled water. After dissolution, $0.2 \mathrm{~mL}$ of DMF and $0.8 \mathrm{~mL}$ of $\mathrm{H}_{2} \mathrm{O}$ were added to the metal and ligand solutions, respectively. Finally, the metal solution was added dropwise and under continuous agitation to the ligand solution. The obtained brown solution was introduced to the oven at $100{ }^{\circ} \mathrm{C}$ for $2 \mathrm{~h}$ in a screw-capped vial $(6 \mathrm{~mL})$ to yield hexagonal single crystals. For the reaction scaling up synthetic procedure, consult the supporting material.

General procedure for the cyanosilylation reaction: In a $1 \mathrm{~mL}$ vial, with a septum screw capped, equipped with a stirring bar, Y/Eu-MOF catalyst $(0.5 \mathrm{~mol} \%)$ was weighed. Subsequently, the corresponding amount of carbonylic compound $\mathbf{1}(0.25 \mathrm{mmol})$ was 
added, followed by trimethylsilyl cyanide (TMSCN) (34 $\mu \mathrm{L}, 0.275$ mmol, 1.1 equiv.), and the reaction was stirred under inert $\mathrm{N}_{2}$ atmosphere at room temperature for $24 \mathrm{~h}$. Once the reaction was finished, the catalyst was removed by centrifugation (12,300 rpm, $5 \mathrm{~min}$ ) and washed with DCM $(2 \times 0.5 \mathrm{~mL})$, obtaining the corresponding pure products 2 and 3 , after removal of the solvent with rotary evaporator. When not full conversion was reached, the product was purified by column chromatography using hexane as eluent.

General procedure for the hydroboration reaction: In a $1 \mathrm{~mL}$ vial, with a septum screw capped, equipped with a stirring bar, Y/Eu-MOF catalyst ( $0.5 \mathrm{~mol} \%)$ was weighed. Subsequently, the corresponding amount of carbonylic compound $\mathbf{1}(0.25 \mathrm{mmol})$ was added, followed by pinacolborane (HBpin) $(40 \mu \mathrm{L}, 0.275 \mathrm{mmol}, 1.1$ equiv.), and the reaction was stirred under inert $\mathrm{N}_{2}$ atmosphere at room temperature for the corresponding time, as indicated on the table. After that time, the hydrolysis of the final product was carried out adding $\mathrm{NaOH}(0.1 \mathrm{M}, 0.5 \mathrm{~mL})$ and $\mathrm{Et}_{2} \mathrm{O}(0.5 \mathrm{~mL})$, and the mixture was stirred overnight. Once the reaction was finished, the catalyst was removed by centrifugation $(12,300 \mathrm{rpm}$, $5 \mathrm{~min})$ and washed with DCM $(2 \times 0.5 \mathrm{~mL})$, obtaining the corresponding product 4 after removal of the solvent with rotary evaporator. When not full conversion was reached the product was purified by column chromatography.

\section{Conclusions}

All in all, to the best of our knowledge, we report the first mixed heterobimetallic Y/Eu-MOF, based on a 3-amino-4-hydroxylbenzoic acid ligand, with impressive catalytic efficiency in the cyanosilylation and hydroboration reaction of carbonyl compounds, but reduced recyclability, compared to the related MOFs. The catalyst has been thoroughly characterized by means of X-ray crystallography, FTIR, ICP-AES, and PXRD; its electrophoretic behavior, as a function of $\mathrm{pH}$, has been also assayed, showing a negative surface charge with a very low tendency to aggregate.

Supplementary Materials: The following supporting information can be downloaded at: https: / / www.mdpi.com/article/10.3390/catal12030299/s1. Table S1: Elemental analysis of compounds Y/Eu-MOF. Table S2: ICP-AES results of compound Y/Eu-MOF. Table S3: Crystallographic data and structure refinement details of compound Y/Eu-MOF. Table S4: Selected bond lengths ( $($ ) and angles $\left({ }^{\circ}\right)$ for compound Y/Eu-MOF. Table S5: Table of the continuous Shape Measurements for the $\mathrm{MN}_{3} \mathrm{O}_{6}$ coordination environment. Table S6: Table of the continuous Shape Measurements for the $\mathrm{MO}_{8}$ coordination environment. Table S7: Electrophoretic mobility and $\zeta$-potential dependence, with the $\mathrm{pH}$ of the $\mathrm{Y} / \mathrm{Eu}-\mathrm{MOF}$ particles dispersed in water. Conductivity fixed at $330 \mu \mathrm{S} / \mathrm{cm}$. Table S8: Optimization of the reaction conditions in the hydroboration reaction. Table S9: Green metrics calculated for Y/Eu-MOF catalyst. Table S10: Catalytic cyanosilylation of benzaldehyde performances of Ln-MOFs, as reported in the literature. Figure S1: Figure of the pattern matching analysis and experimental PXRD for Y/Eu-MOF. Figure S2: Figure of the infrared spectra of the ligand and $\mathrm{Y} / \mathrm{Eu}-\mathrm{MOF}$. Figure S3: SEM and EDS mapping of bulk material of $\mathrm{Y} / \mathrm{Eu}-\mathrm{MOF}$. Figure S4: Images and particle size distribution (an overall of 250 particles) in the deposited fraction of $\mathrm{Y} / \mathrm{Eu}-\mathrm{MOF}$ catalyst non-suspended in water (about a $68 \%$ of the total amount), determined from optical microscope images. Figure S5: Images and particle size distribution (an overall of 250 particles) of $\mathrm{Y} / \mathrm{Eu}-\mathrm{MOF}$ crystals in the fraction steadily suspended in water (about a 32\% of the total amount), determined from optical microscope images. Figure S6: Comparation of the particle size distribution of $\mathrm{Y} / \mathrm{Eu}-\mathrm{MOF}$ in the fraction steadily suspended in water and the non-suspended, determined from optical microscope images. Figure S7: Calibration line of conductivity $(\mu \mathrm{S} / \mathrm{cm})$ vs $[\mathrm{NaCl}](\mathrm{mol} / \mathrm{L})$. Figure S8: $\zeta$-potential $(\mathrm{mV})$ dependence with the $\mathrm{pH}$ of the $\mathrm{Y} / \mathrm{Eu}-\mathrm{MOF}$. All the measurements were performed with constant conductivity of $330 \mu \mathrm{S} / \mathrm{cm}$. Figure S9: Electrophoretic mobility $(\mu \mathrm{m} \cdot \mathrm{cm} / \mathrm{V} \cdot \mathrm{s})$ dependence with the $\mathrm{pH}$ of the $\mathrm{Y} / \mathrm{Eu}-\mathrm{MOF}$. All the measurements were performed with constant conductivity of $330 \mu \mathrm{S} / \mathrm{cm}$. Figure S10: Study of the recyclability of Y/Eu-MOF $(0.5 \mathrm{~mol} \%)$ catalyst on the cyanosilylation and hydroboration reaction of acetophenone as carbonyl substrate. Figure S11: Analysis of the TOF $\left(\mathrm{h}^{-1}\right)$ obtained in the cyanosilylation reaction of acetophenone at different times of reaction with $\mathrm{Y} / \mathrm{Eu}-\mathrm{MOF}(0.5 \mathrm{~mol} \%)$, with the optimized reaction conditions. Figure S12: Analysis of the TOF $\left(\mathrm{h}^{-1}\right)$ obtained in the hydroboration reaction acetophenone at different times of reaction with $\mathrm{Y} / \mathrm{Eu}-\mathrm{MOF}(0.5 \mathrm{~mol} \%)$, with the optimized reaction conditions. Scheme S1: Reaction conditions 
used for the study of recyclability of $\mathrm{Y} / \mathrm{Eu}-\mathrm{MOF}$ catalysts in the cyanosilylation reaction. Scheme S2: Reaction conditions used for the study of recyclability of $\mathrm{Y} / \mathrm{Eu}-\mathrm{MOF}$ catalysts in the hydroboration reaction. Scheme S3: Leaching test, carried out after the first and second cycles.

Author Contributions: Conceptualization, I.F. and A.R.-D.; methodology, M.E.L.-V., J.M.P. and E.E.-E.; software, S.R., D.C.-L. and J.M.S.; validation, J.M.P., S.R. and J.M.S.; formal analysis, A.R.-D.; investigation, M.E.L.-V., J.M.P. and E.E.-E.; resources, I.F., J.M.S. and A.R.-D.; data curation, S.R. and D.C.-L.; writing-original draft preparation, J.M.P. and E.E.-E.; writing-review and editing, J.M.P. and S.R.; visualization, I.F.; supervision, A.R.-D.; project administration, I.F.; funding acquisition, A.R.-D., I.F. and J.M.S. All authors have read and agreed to the published version of the manuscript.

Funding: This research has been funded by the State Research Agency (grants CTQ2017-84334-R and PGC2018-102052-B-C21) of the Spanish Ministry of Science, Innovation and Universities, the European Union (European Regional Development Fund-ERDF), Junta de Andalucía (P20_01041, UAL2020-AGR-B1781, B-FQM-734-UGR20 and FQM-394). E.E., S.R., and J.P. acknowledge the Government of the Basque Country, Juan de la Cierva Incorporación (grant no. IJC2019-038894-I) and University of Almeria (grant no. HIPATIA2021_04) for their respective fellowships.

Data Availability Statement: More data can be obtained by request from authors.

Conflicts of Interest: The authors declare no conflict of interest.

\section{References}

1. Bavykina, A.; Kolobov, N.; Khan, I.S.; Bau, J.A.; Ramirez, A.; Gascon, J. Metal-organic frameworks in heterogeneous catalysis: Recent progress, new trends, and future perspectives. Chem. Rev. 2020, 120, 8468-8535. [CrossRef]

2. Yadav, A.; Kanoo, P. Metal-organic frameworks as platform for lewis-acid-catalyzed organic transformations. Chem. Asian J. 2019, 14, 3531-3551. [CrossRef] [PubMed]

3. Mo, K.; Yang, Y.; Cui, Y. A homochiral metal-organic framework as an effective asymmetric catalyst for cyanohydrin synthesis. J. Am. Chem. Soc. 2014, 136, 1746-1749. [CrossRef] [PubMed]

4. Hu, Z.; Zhao, D. Metal-organic frameworks with Lewis acidity: Synthesis, characterization, and catalytic applications. CrystEngComm 2017, 19, 4066-4081. [CrossRef]

5. Dvries, R.F.; Iglesias, M.; Snejko, N.; Gutiérrez-Puebla, E.; Monge, M.A. Lanthanide metal-organic frameworks: Searching for efficient solvent-free catalysts. Inorg. Chem. 2012, 51, 11349-11355. [CrossRef] [PubMed]

6. Zhang, Z.; Chen, J.; Bao, Z.; Chang, G.; Xing, H.; Ren, Q. Insight into the catalytic properties and applications of metal-organic frameworks in the cyanosilylation of aldehydes. RSC Adv. 2015, 5, 79355-79360. [CrossRef]

7. Alzamly, A.; Bakiro, M.; Hussein Ahmed, S.; Alnaqbi, M.A.; Nguyen, H.L. Rare-earth metal-organic frameworks as advanced catalytic platforms for organic synthesis. Coord. Chem. Rev. 2020, 425, 213543. [CrossRef]

8. Gawronski, J.; Wascinska, N.; Gajewy, J. Recent progress in Lewis base activation and control of stereoselectivity in the additions of trimethylsilyl nucleophiles. Chem. Rev. 2008, 108, 5227-5252. [CrossRef]

9. Batista, P.K.; Alves, D.J.M.; Rodrigues, M.O.; De Sá, G.F.; Junior, S.A.; Vale, J.A. Tuning the catalytic activity of lanthanide-organic framework for the cyanosilylation of aldehydes. J. Mol. Catal. A Chem. 2013, 379, 68-71. [CrossRef]

10. Evans, O.R.; Ngo, H.L.; Lin, W. Chiral porous solids based on lamellar lanthanide phosphonates. J. Am. Chem. Soc. 2001, 123, 10395-10396. [CrossRef]

11. Wang, X.; Zhang, L.; Yang, J.; Liu, F.; Dai, F.; Wang, R.; Sun, D. Lanthanide metal-organic frameworks containing a novel flexible ligand for luminescence sensing of small organic molecules and selective adsorption. J. Mater. Chem. A 2015, 3, 12777-12785. [CrossRef]

12. Liu, X.; Lin, H.; Xiao, Z.; Fan, W.; Huang, A.; Wang, R.; Zhang, L.; Sun, D. Multifunctional lanthanide-organic frameworks for fluorescent sensing, gas separation and catalysis. Dalton Trans. 2016, 45, 3743-3749. [CrossRef] [PubMed]

13. An, H.; Wang, L.; Hu, Y.; Fei, F. Temperature-induced racemic compounds and chiral conglomerates based on polyoxometalates and lanthanides: Syntheses, structures and catalytic properties. CrystEngComm 2015, 17, 1531-1540. [CrossRef]

14. Fei, F.; An, H.; Meng, C.; Wang, L.; Wang, H. Lanthanide-supported molybdenum-vanadium oxide clusters: Syntheses, structures and catalytic properties. RSC Adv. 2015, 5, 18796-18805. [CrossRef]

15. Echenique-Errandonea, E.; Pérez, J.M.; Rojas, S.; Cepeda, J.; Seco, J.M.; Fernández, I.; Rodríguez-Diéguez, A. A novel yttriumbased metal-organic framework for the efficient solvent-free catalytic synthesis of cyanohydrin silyl ethers. Dalton Trans. 2021, 50, 11720-11724. [CrossRef] [PubMed]

16. Pérez, J.M.; Rojas, S.; García-García, A.; Montes-Andrés, H.; Martínez, C.R.; Romero-Cano, M.S.; Choquesillo-Lazarte, D.; Abdelkader-Fernández, V.K.; Pérez-Mendoza, M.; Cepeda, J.; et al. Catalytic Performance and Electrophoretic Behavior of an Yttrium-Organic Framework Based on a Tricarboxylic Asymmetric Alkyne. Inorg. Chem. 2022, 61, 1377-1384. [CrossRef] 
17. Dvries, R.F.; De La Peña-Oshea, V.A.; Snejko, N.; Iglesias, M.; Gutiérrez-Puebla, E.; Monge, M.Á. Insight into the correlation between net topology and ligand coordination mode in new lanthanide MOFs heterogeneous catalysts: A theoretical and experimental approach. Cryst. Growth Des. 2012, 12, 5535-5545. [CrossRef]

18. Dvries, R.F.; Snejko, N.; Iglesias, M.; Gutiérrez-Puebla, E.; Monge, M.A. Ln-MOF pseudo-merohedral twinned crystalline family as solvent-free heterogeneous catalysts. Cryst. Growth Des. 2014, 14, 2516-2521. [CrossRef]

19. Gomez, G.E.; Kaczmarek, A.M.; Van Deun, R.; Brusau, E.V.; Narda, G.E.; Vega, D.; Iglesias, M.; Gutierrez-Puebla, E.; Monge, M.Á. Photoluminescence, unconventional-range temperature sensing, and efficient catalytic activities of lanthanide metal-organic frameworks. Eur. J. Inorg. Chem. 2016, 2016, 1577-1588. [CrossRef]

20. Gomez, G.E.; Brusau, E.V.; Sacanell, J.; Soler Illia, G.J.A.A.; Narda, G.E. Insight into the metal content-structure-property relationship in lanthanide metal-organic frameworks: Optical studies, magnetism, and catalytic performance. Eur. J. Inorg. Chem. 2018, 2018, 2452-2460. [CrossRef]

21. Gustafsson, M.; Bartoszewicz, A.; Martiín-Matute, B.; Sun, J.; Grins, J.; Zhao, T.; Li, Z.; Zhu, G.; Zou, X. A family of highly stable lanthanide metal-organic frameworks: Structural evolution and catalytic activity. Chem. Mater. 2010, 22, 3316-3322. [CrossRef]

22. He, H.; Ma, H.; Sun, D.; Zhang, L.; Wang, R.; Sun, D. Porous lanthanide-organic frameworks: Control over interpenetration, gas adsorption, and catalyst properties. Cryst. Growth Des. 2013, 13, 3154-3161. [CrossRef]

23. Karmakar, A.; Rúbio, G.M.D.M.; Paul, A.; Guedes da Silva, M.F.C.; Mahmudov, K.T.; Guseinov, F.I.; Carabineiro, S.A.C.; Pombeiro, A.J.L. Lanthanide metal organic frameworks based on dicarboxyl-functionalized arylhydrazone of barbituric acid: Syntheses, structures, luminescence and catalytic cyanosilylation of aldehydes. Dalton Trans. 2017, 46, 8649-8657. [CrossRef] [PubMed]

24. Wu, P.; Wang, J.; Li, Y.; He, C.; Xie, Z.; Duan, C. Luminescent Sensing and Catalytic Performances of a Multifunctional LanthanideOrganic Framework Comprising a Triphenylamine Moiety. Adv. Funct. Mater. 2011, 21, 2788-2794. [CrossRef]

25. Huang, Z.; Liu, D.; Camacho-Bunquin, J.; Zhang, G.; Yang, D.; López-Encarnación, J.M.; Xu, Y.; Ferrandon, M.S.; Niklas, J.; Poluektov, O.G.; et al. Supported Single-Site Ti(IV) on a Metal-Organic Framework for the Hydroboration of Carbonyl Compounds. Organometallics 2017, 36, 3921-3930. [CrossRef]

26. Newar, R.; Akhtar, N.; Antil, N.; Kumar, A.; Shukla, S.; Begum, W.; Manna, K. Amino Acid-Functionalized Metal-Organic Frameworks for Asymmetric Base-Metal Catalysis. Angew. Chemie Int. Ed. 2021, 60, 10964-10970. [CrossRef] [PubMed]

27. Antil, N.; Akhtar, N.; Newar, R.; Begum, W.; Kumar, A.; Chauhan, M.; Manna, K. Chiral Iron(II)-Catalysts within Valinol-Grafted Metal-Organic Frameworks for Enantioselective Reduction of Ketones. ACS Catal. 2021, 11, 10450-10459. [CrossRef]

28. Zhang, T.; Manna, K.; Lin, W. Metal-organic frameworks stabilize solution-inaccessible cobalt catalysts for highly efficient broad-scope organic transformations. J. Am. Chem. Soc. 2016, 138, 3241-3249. [CrossRef] [PubMed]

29. Manna, K.; Ji, P.; Greene, F.X.; Lin, W. Metal-organic framework nodes support single-site magnesium-alkyl catalysts for hydroboration and hydroamination reactions. J. Am. Chem. Soc. 2016, 138, 7488-7491. [CrossRef] [PubMed]

30. Manna, K.; Ji, P.; Lin, Z.; Greene, F.X.; Urban, A.; Thacker, N.C.; Lin, W. Chemoselective single-site Earth-abundant metal catalysts at metal-organic framework nodes. Nat. Commun. 2016, 7, 1-11. [CrossRef] [PubMed]

31. Blatov, V.A.; Shevchenko, A.P.; Proserpio, D.M. Applied topological analysis of crystal structures with the program package topospro. Cryst. Growth Des. 2014, 14, 3576-3586. [CrossRef]

32. Spek, A.L. Structure validation in chemical crystallography. Acta Crystallogr. Sect. D Biol. Crystallogr. 2009, 65, 148-155. [CrossRef] [PubMed]

33. Bage, A.D.; Hunt, T.A.; Thomas, S.P. Hidden boron catalysis: Nucleophile-promoted decomposition of HBpin. Org. Lett. 2020, 22, 4107-4112. [CrossRef] [PubMed] 